\title{
SPATIAL COHERENCE OF WINDS AND WAVES OVER THE ARABIAN SEA AND BAY OF BENGAL AND THEIR EVOLUTION DURING SW MONSOON: A NOVEL APPLICATION OF ALONG-TRACK RADAR ALTIMETER MEASUREMENTS FROM SPACE
}

\author{
Satyendra. M. Bhandari ${ }^{\mathrm{a}}$, K. Hareef baba shaeb ${ }^{\mathrm{b}, *}$ \\ a Indian Centre for Climate and Societal Impacts Research (ICCSIR), Mandvi (Gujarat), India - satyendra_bhandari@yahoo.com \\ ${ }^{\mathrm{b}}$ Regional Remote Sensing Centre (Central), NRSC, ISRO-DOS, Nagpur, India - babaphyiway@gmail.com
}

KEY WORDS: Oceanic winds and waves, spatial coherence, SW Monsoon, Radar Altimeter

\begin{abstract}
:
We have examined, for the first time, the spatial coherence of oceanic parameters, namely, the ocean surface wind and significant wave height (SWH), using near-instantaneous along-track sampling over vast oceanic tracks provided by Poseidon-2 Radar Altimeter onboard Jason-1. The spatial coherence length scales over the Arabian Sea and the Bay of Bengal regions, derived using Auto correlation analysis, display interesting characteristics in relation to onset and evolution of SW Monsoon over India. The estimated spatial coherence scales are found to be of the order of 100-500 km. Generally, SWH coherence lengths over Arabian Sea are observed to increase from June to July during good monsoon year (2012). This trend is not followed for the poor monsoon year (2002). Similar trend is observed for spatial coherence scales for wind speed. The temporal evolution of analyzed spatial coherence scales of winds and waves over Arabian Sea clearly brings out the distinction between a 'good' (2012) and a 'poor' (2002) monsoon year. The spatial coherence lengths of these parameters over the Bay of Bengal are found to be shorter and do not show any systematic relation to onset and evolution of SW monsoon. Anisotropy in coherence lengths is also analyzed by treating ascending and descending tracks separately. Generally, the descending tracks measurements show higher spatial coherence lengths than the ascending ones. Like the spatial coherence scales, the anisotropy of the coherence scales over the Arabian Sea also mimics the behaviour of the strength of SW Monsoon.
\end{abstract}

\section{INTRODUCTION}

Over the last more than two decades, precise dual frequency Radar Altimetry measurements from space have revolutionized many aspects of Oceanography. In addition, application of such RA data from Topex and subsequent follow on missions have also been exploited for estimation of rainfall over the oceans for the first time by Bhandari and Varma (1996) and subsequently developed extensively by others (Chen et al.,1997). TOPEX dual frequency Radar Altimeter (RA) mission was launched in 1992. Since then continuity of such precise dual-frequency radar altimetry measurements has been maintained through Jason-1 and Jason-2, FY-2 etc. In parallel, decade-long RA measurements have also been collected by ESA's polar orbiting ENVISAT. More recently, the successful launch of Indo-French SARAL-ALTIKA satellite mission with a radar altimeter operating, for the first time, in the Ka band has added a new dimension to radar altimetry from space. These RA datasets represent a goldmine for a variety of interesting research studies.

Altimeter data can be used to infer the ocean surface significant wave height and wind speed from an examination of the shape and amplitude of the return radar signal (Fedor et.al., 1982).Significant wave height (SWH) is traditionally defined as the average of the one third highest wave heights observed at sea, which is estimated based on the slope of the leading edge of the returned waveform.
The estimate of temporal and spatial variability of SWH in the mesoscale range ( 1 hour to 3 days, 30 to $100 \mathrm{~km}$ ) is critical not only for studies of oceanic and atmospheric processes but also in the calibration/Validation process of satellite- borne wave sensors as well as for the prediction of extreme values of environmental parameters (Tournadre, 1993). Knowledge about temporal and spatial scales is necessary, when calibrating a wave sensor, to estimate the effects of the spatial and temporal separations between in situ and satellite measurements (Monaldo, 1988; Monaldo, 1990).

The strength of the returned radar echo depends strongly on the surface roughness and the incidence angle of the radiation. As the wind speed increases the sea surface roughness increases and a greater fraction of the incident radiation is reflected away from the incident direction. At incidence angles near nadir, the power of the backscattered radiation is inversely related to wind speed but is not sensitive to wind direction (Chelton et al., 1985). Altimeter provides measurement of wind speed in this small incidence angle regime. Winds over the ocean influence air-sea exchanges of heat, moisture, gases and particulates. Winds create waves and currents. These are responsible for global and regional weather and climate e.g. El Niño over tropical Pacific. Over polar oceans, sea ice formation and dynamics is controlled by winds. Knowledge of the wind speed is essential for studies of latent heat flux (Liu et.al, 1984;

* Corresponding author 
Halpern et al., 1983) and for other potential engineering applications e.g. winds and wave power generation.

The auto covariance of any parameter provides a measure of the cross-correlation of its variability at points separated in time and space. If a large region fluctuates in unison, then the auto covariance will be high and will decrease slowly as a function of distance. If spatial fluctuations occur over short distances, then measurements taken at nearby points will be un correlated, so that auto covariance will decrease rapidly with distance. Similarly, the time scales over which the auto covariance decreases indicate the temporal scales of variability of measured data (Gille et al, 1996). Knowledge of 'coherence' is also essential for making a valid comparison between remotely sensed and in-situ measurements.The information is essential for recent developments in ocean data assimilation that needs realistic decorrelation scales. The decorrelation scale is an indicator of an "effective radius of observation" for analysis procedures. Knowledge of the decorrelation scale of ocean variability in space and time is also essential for the design of an effective observing system (Ocean Observing System Devel-opment Panel (OOSDP), 1995).

The onset and evolution of SW Monsoon over the Indian region, during June to September every year, is associated with the arrival and strengthening of moisture laden southwesterly winds over the Arabian Sea region. A branch of this inflow also reaches the Bay of Bengal. While there have been many studies investigating the temporal characteristics of winds and waves over the Arabian Sea and their impacts on SW monsoon over India using both the in-situ and space based measurements (Brandt et al., 2003), so far there have been no attempts to study the spatial coherence of wind and wave fields in relation to the SW Monsoon over India. As far back as 1985, one of us Bhandari (1985) proposed a study of spatial and temporal coherence based on Radar Altimeter data from space and in-situ measurements from ships and buoys respectively. Subsequently, Sarkar et al. (2002; 2006) dealt with auto correlation analysis of surface wind vectors and wave heights measured using the deep sea buoys located over the Bay of Bengal to estimate temporal de-correlation time scales. Later, several studies (Chu et al., 2002; Romanou et al., 2006) focused on the temporal decorrelation time scales of sea surface properties. There is very little attention in literature on understanding the spatial decorrelation scales of oceanic parameters.

Buoys produce long duration continuous time series of oceanic measurements but have a very sparse geographical distribution and sampling, whereas radar altimeters in Earth's orbit provide uniform, global, repetitive measurements extending over many years. Here we exploit, for the first time, the availability of high resolution along track measurements of oceanic winds and waves by space-borne Radar Altimeters for 'spatial' coherence studies. These along track measurements represent nearinstantaneous spatial transects of wind and wave fields over the ocean. As an example, the entire latitudinal expanse of the Arabian Sea is traversed by an orbiting Radar Altimeter in a short span of about 5 minutes.

In this study, we analyze these near-instantaneous along track Radar Altimeter measurements, of winds and waves over the Indian monsoon region, to estimate their spatial coherence scales using spatial auto-correlation analyses, and study their relation with monsoon activity.

\section{STUDY REGION}

The main focus of this paper is to understand the spatial coherence scales of winds and waves over the Arabian Sea and Bay of Bengal in relation to evolution of southwest monsoon over India. Six Jason-1 ground tracks, 3 ascending and 3 descending over Arabian Sea and similarly over Bay of Bengal have been selected for analysis. The size of the domain can play an important role, because fields of SWH are typically not homogenous over the ocean. Generally, the larger the area considered, the larger the length scale of the correlation. As expected, the correlations are highest at short distances and decay toward longer distances (Queffeulou et al, 2007). We have considered the Arabian Sea and Bay of Bengal tracks starting from equator to northernmost point where it approaches the Indian landmass.

Figure 1 shows global coverage of ground tracks corresponding to one full cycle of Jason -1 with extracted tracks of interest highlighted in color. Figure 2 shows the ground tracks of interest around Indian sub continent.

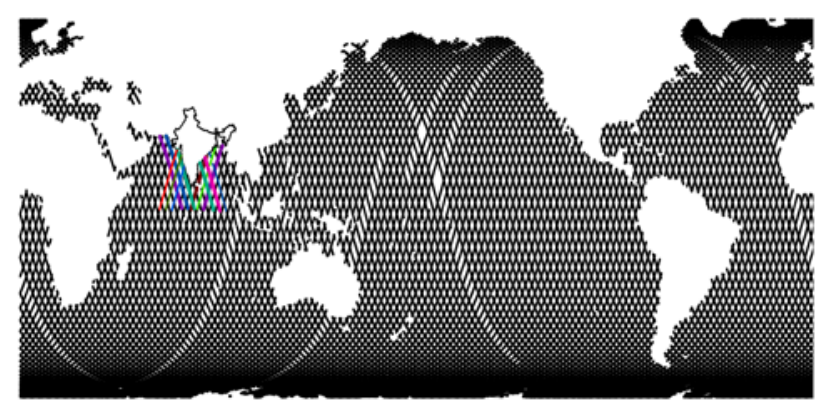

Fig. 1 - Ground tracks corresponding to one full cycle of Jason 1 with extracted tracks of interest being highlighted in color.

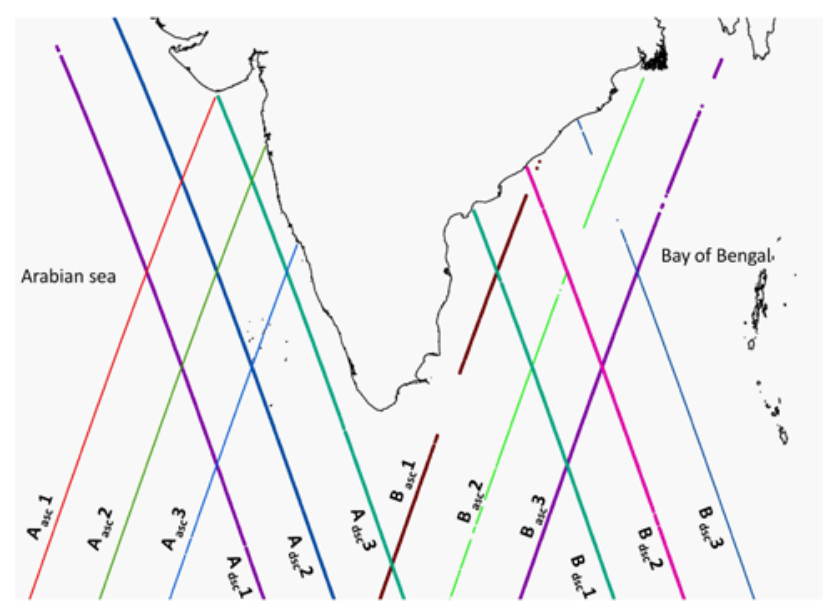

Fig. 2 - Extracted ground tracks of interest over the Arabian Sea and Bay of Bengal around the Indian sub-continent.

Nomenclature for the tracks for further analysis has been tabulated in Table.1. 
Table 1: Nomenclature used for the extracted tracks for analysis

\begin{tabular}{cccc}
\hline $\begin{array}{c}\text { Arabian } \\
\text { Sea }\end{array}$ & \multicolumn{1}{c}{ Track } & $\begin{array}{c}\text { Bay of } \\
\text { Bengal }\end{array}$ & Track \\
\hline $\mathrm{A}_{\mathrm{asc}} 1$ & Ascending & $\mathrm{B}_{\mathrm{asc}} 1$ & Ascending \\
\hline $\mathrm{A}_{\mathrm{asc}} 2$ & Ascending & $\mathrm{B}_{\mathrm{asc}} 2$ & Ascending \\
\hline $\mathrm{A}_{\mathrm{asc}} 3$ & Ascending & $\mathrm{B}_{\mathrm{asc}} 3$ & Ascending \\
\hline $\mathrm{A}_{\mathrm{dsc}} 1$ & Descending & $\mathrm{B}_{\mathrm{dsc}} 1$ & Descending \\
\hline $\mathrm{A}_{\mathrm{dsc}} 2$ & Descending & $\mathrm{B}_{\mathrm{dsc}} 2$ & Descending \\
\hline $\mathrm{A}_{\mathrm{dsc}} 3$ & Descending & $\mathrm{B}_{\mathrm{dsc}} 3$ & Descending \\
\hline
\end{tabular}

\section{DATA AND ANALYSIS}

\subsection{Data}

Jason-1 is a follow on mission to the highly successful TOPEX/POSEIDON (T/P) mission. The Jason-1 measurement covers the same ground tracks as the original T/P with a 254 orbit, 10-day exact repeat cycle. The Poseidon-2 altimeter, onboard Jason-1, operating at $13.575 \mathrm{GHz}$ (Ku band) and 5.3 $\mathrm{GHz}$ ( $\mathrm{C}$ band), is the nadir pointing radar that measures the range between the satellite and the ocean surface. The measurements made at the two frequencies are combined to obtain measurements of the altimeter range, wind speed, significant wave height, and the ionospheric correction. Measurements of the return signal characteristics provide estimates of the back scattering coefficient, and the received power as a function of time. The slope of the leading edge of the received echo is a function of the SWH (Brown, 1979). The instrument was designed to measure $\mathrm{SWH}$ with a precision of $10 \%$ or $0.5 \mathrm{~m}$ (whichever is greater). The backscattering coefficient is used to estimate-the wind speed with an accuracy of $1.7 \mathrm{~m} / \mathrm{s}$ (AVISO and PODAAC User Handbook, 2008). The altimeter data provides these estimates every second, or approximately every $7 \mathrm{Km}$, along the satellite ground track. Table 2 shows the list of data cycles used in the present study.

Table 2: Jason-1 data cycles used in the present study

\begin{tabular}{lcc}
\hline Year 2002 & Month & Year 2012 \\
\hline cycle 1 & JANUARY & cycle 370 \\
\hline cycle 13 & MAY & cycle 501 \\
\hline cycle 16 & JUNE & cycle 504 \\
\hline cycle 20 & JULY & cycle 507 \\
\hline
\end{tabular}

Data from the Jason-1 satisfy continuous (or periodic) data acquisition with near global ocean coverage, which makes it possible to investigate the typical/dominant spatial and temporal scales of ocean variabilities. For SWH we have used Aviso Delayed Time mono-mission Corrected Sea Surface Heights (DT CorSSH) and Sea Level Anomalies (DT SLA) product for the years 2002 and 2012. For Reference products, corrections are stable all along the period provided. Basically, Reference products are made for users who need to work on the most historically homogeneous time series. Each file corresponds to a complete orbital cycle. These data are corrected for instrumental, environmental (wet tropospheric, dry tropospheric and ionospheric effects) and geophysical (ocean tide, earth tide and pole tide) perturbations. These products are distributed by AVISO and produced by CLS Space Oceanography Division and distributed by AVISO, with support from CNES (http://www.aviso.oceanobs.com) For wind speed, we have used wind/wave delayed time products listed in AVISO website. The data is provided as one pass per file (http://www.aviso.oceanobs.com).

\subsection{Auto Correlation Function (ACF) Analysis}

Spatial Autocorrelation measures correlations between observations a certain distance apart. Based on the ordinary correlation coefficient, we can see if successive observations are correlated. A lag is defined as the number of steps by which a data series is shifted relative to itself (when auto correlated). An autocorrelation coefficient at lag $\mathrm{k}$ can be found by the following equation

$$
r_{k}=\frac{\sum_{t=1}^{N-k}\left(X_{t}-\bar{x}\right)\left(X_{t+k}-\bar{x}\right)}{\sum_{t=1}^{N-k}\left(X_{t}-\bar{x}\right)^{2}}
$$

Where $x_{t}$ is a data value at step $\mathbf{t}, \mathbf{k}$ is the lag, and the overall mean is given by

$$
\bar{x}=\sum_{t=1}^{N-k} \frac{x_{t}}{N}
$$

The spatial coherence scale is defined here as the lag at which the auto correlation drops to the value of 0.5 . Figure 3 shows an example calculation for one particular along track data series of SWH for which spatial coherence scale is estimated to be about 40 lags (nearly $300 \mathrm{~km}$ ).

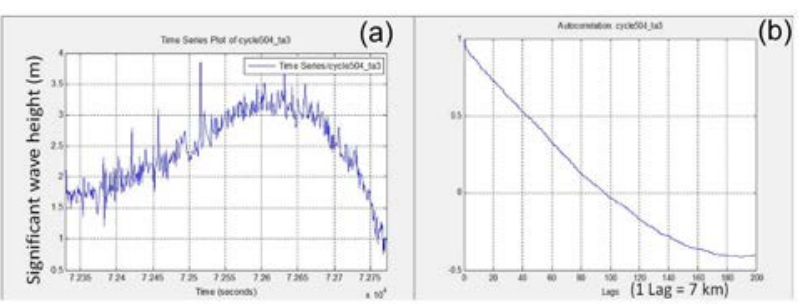

Fig. 3 - Example of the auto correlation analysis (a) along track time series of SWH (b) Auto correlation function.

Sometimes, during the analysis we observed ACF falling very sharply within a few lags. A look at the corresponding data, wind speed in this case, reveals the erroneous or spurious nature of measurements. Such measurements are not considered in the present analysis.

\section{RESULTS AND DISCUSSION}

The results of the spatial coherence analysis of ocean state parameters namely SWH and, Wind Speed are presented in the following sections.

\subsection{Significant Wave Height}

SW monsoon activity over India is dependent on arrival and 
build up of Southwesterly winds that bring sufficient moisture towards Indian landmass. For the year 2012, Fig.4 (a) shows that over the Arabian Sea, the spatial coherence scales consistently increase from May to August, as highly sustained SW monsoon winds pick up. From May to September, winds in this region blow persistently from the southwest, and so during this time period the fetch for this area is relatively long, stretching from the east African coast. On the other hand, as shown in Figure 4(b) for the year 2002 over the Arabian Sea, the spatial coherence scales initially show an increasing trend, and then decrease for all tracks except $\mathrm{A}_{\mathrm{asc}} 3$. On the other hand, as shown in Figure 4(c) and Figure 4(d), no significant trends are seen over the Bay of Bengal. The coherence scale lengths are observed to be higher in Arabian Sea than over Bay of Bengal. This is because, the monsoon activity in Bay of Bengal incorporates many mesoscale and small features of circulation e.g. the monsoon lows and depressions. This makes the wind and wave field more structured and complex, leading to smaller coherence lengths. More studies are required to understand the processes occurring over this region and their role in influencing the spatial coherence scales.
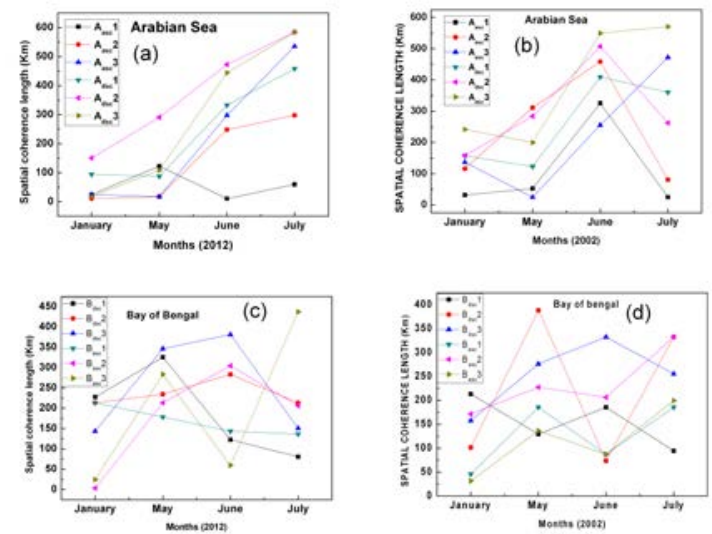

Fig. 4 - Spatial coherence lengths of SWH in (a) Arabian Sea for the year 2012 (b) Arabian Sea for the year 2002 (c) Bay of Bengal for the year 2012 (d) Bay of Bengal for the year 2002.

According to India Meteorological Department (IMD) report, July 2002 registered the worst ever rainfall deficiency of $49 \%$ in the history of recorded observations, whereas July 2012 registered a rainfall deficiency which was within $10 \%$ of normal (www.imd.gov.in). The temporal evolution of analyzed spatial coherence scales over Arabian Sea, as seen in Fig. 5 clearly brings out the distinction between a 'good' (2012) and a 'poor' (2002) monsoon year.

Figure 5 and 6 show how the distribution of SWH values themselves changes over the Arabian Sea and Bay of Bengal as monsoon approached during two different contrasting monsoon years 2012 and 2002.

Important point to note is the signature of the monsoon in the Arabian Sea, where an enlarging area of high SWH develops during monsoon for 2012. On the other hand, for the year 2002, SWH reaches to maximum in the month of June and suddenly registers a fall in the month of July. Thus it is seen that the magnitude of SWH as well as the spatial coherence lengths of SWH are highly correlated with the onset and evolution of SW Monsoon activity.
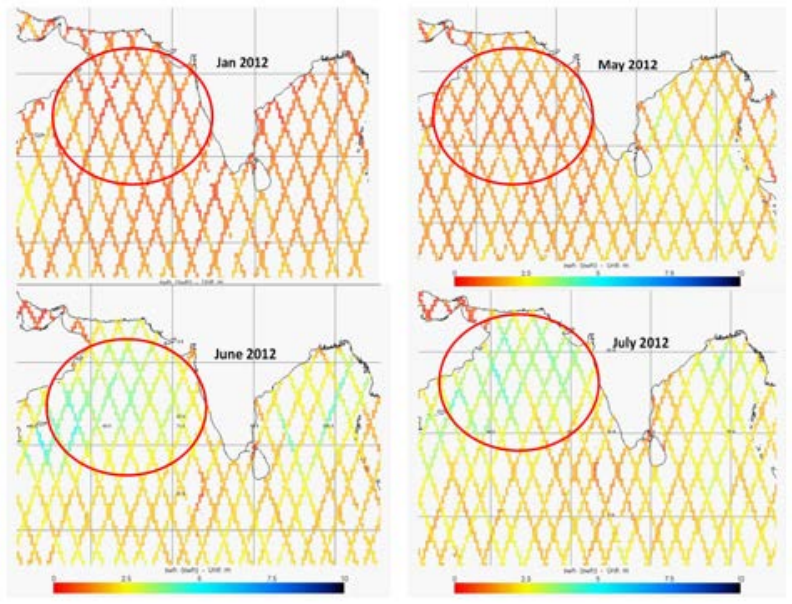

Fig. 5 - Monthly evolution of SWH during 2012 Monsoon season
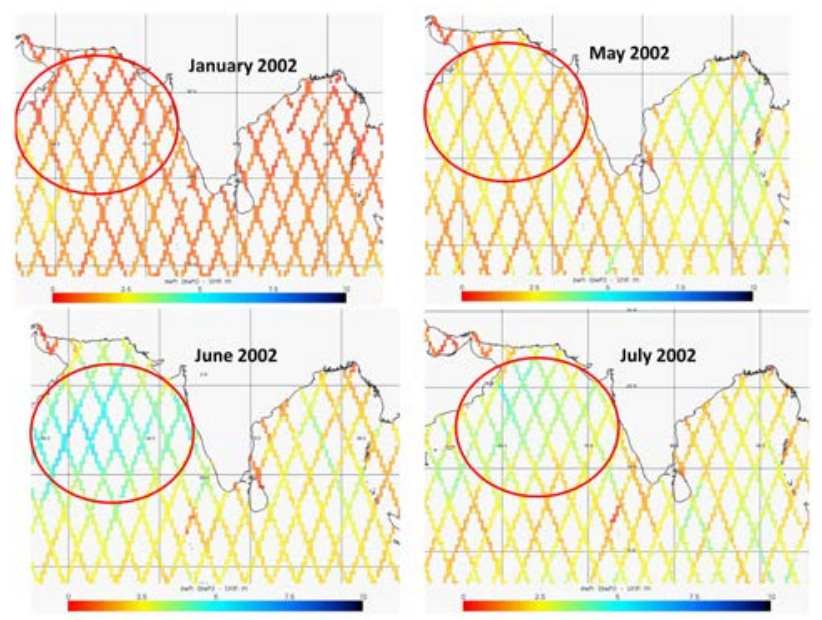

Fig. 6 - Monthly evolution of SWH during 2002 Monsoon season

\subsection{Wind speed}

The characteristic modification of the narrow altimeter pulse by reflection from the rough ocean surface permits the inference of both wind speed and SWH. Wind speed is calculated from the mathematical relationship with the $\mathrm{Ku}$ band backscatter coefficient and the significant wave height (Brown, 1979).

The spatial coherence length scales of wind speed estimated for all the ascending and descending orbits over the Arabian Sea and Bay of Bengal are plotted in the Figure 7 and show a similar trend as seen in the case of significant wave height (SWH).The effect of sustained presence of the south-westerly winds responsible for the SW Indian monsoon is clearly observed. Missing data points refers to cases of abrupt fall in ACF which has been discussed in section 3.1. 

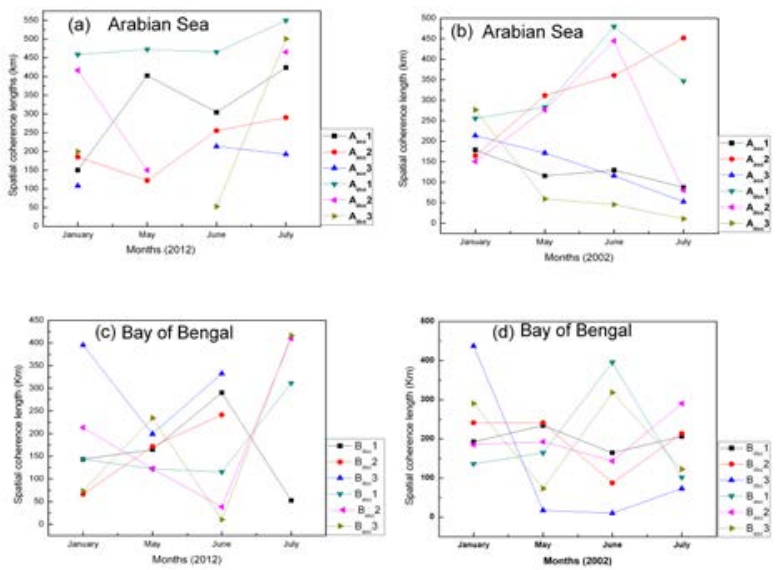

Fig. 7 - Spatial coherence lengths for wind speed in (a) Arabian Sea for the year 2012 (b) Arabian Sea for the year 2002 (c) Bay of Bengal for the year 2012 (d) Bay of Bengal for the year 2002

Table 3: Spatial Coherence Lengths of Oceanic parameter during 2012 and 2002 SW Monsoons

\begin{tabular}{|l|l|l|l|l|l|}
\hline Parameter & $\begin{array}{l}\text { SW } \\
\text { Monsoon }\end{array}$ & \multicolumn{2}{|c|}{ Arabian Sea } & \multicolumn{2}{c|}{$\begin{array}{l}\text { Bay of } \\
\text { Bengal }\end{array}$} \\
\hline & & $\begin{array}{l}\text { Min. } \\
\text { (km) }\end{array}$ & $\begin{array}{l}\text { Max. } \\
(\mathbf{k m})\end{array}$ & $\begin{array}{l}\text { Min. } \\
(\mathbf{k m})\end{array}$ & $\begin{array}{l}\text { Max. } \\
(\mathbf{k m})\end{array}$ \\
\hline \multirow{2}{*}{ SWH } & $\mathbf{2 0 1 2}$ & 10.5 & 584.5 & 3.5 & 437.5 \\
\cline { 2 - 6 } & $\mathbf{2 0 0 2}$ & 24.5 & 570.5 & 31.5 & 388.5 \\
\hline & & & & & \\
\hline \multirow{2}{*}{$\begin{array}{l}\text { Wind } \\
\text { Speed }\end{array}$} & $\mathbf{2 0 1 2}$ & 52.5 & 549.5 & 10.5 & 416.5 \\
\cline { 2 - 6 } & $\mathbf{2 0 0 1}$ & 10.5 & 479.5 & 10.5 & 437.5 \\
\hline
\end{tabular}

The derived values of spatial coherence lengths for both the ocean parameters of interest are tabulated in Table. 3

\subsection{Anisotropy in spatial Coherence Scales}

A look at the RA ground tracks in Figure 1 and Figure 2 shows that the radar altimeter samples the oceanic regions over India in two different directions, along ascending and descending tracks. Although the difference between two angles is not very large, still, there is a possibility to investigate whether the spatial coherence displays any anisotropy. To obtain anisotropic correlations from the altimeter data, the along-track spatial auto-correlations from ascending and descending ground tracks are examined separately. This produces two length scales, one along the ascending tracks alone, $A_{\text {asc }}$, and one along the descending tracks alone, $A_{\mathrm{dsc}}$.

Figure 8 shows the anisotropy between ascending and descending orbits, with the descending tracks showing higher spatial coherence lengths than the ascending ones. This can be partially attributed to the fact that the descending tracks over the Arabian Sea are largely away and free of shallow bathymetric regions of the continental shelf and represents open ocean conditions. On the other hand, some portion of the ascending tracks over the Arabian Sea pass over shallow seas, islands and coastal areas etc.
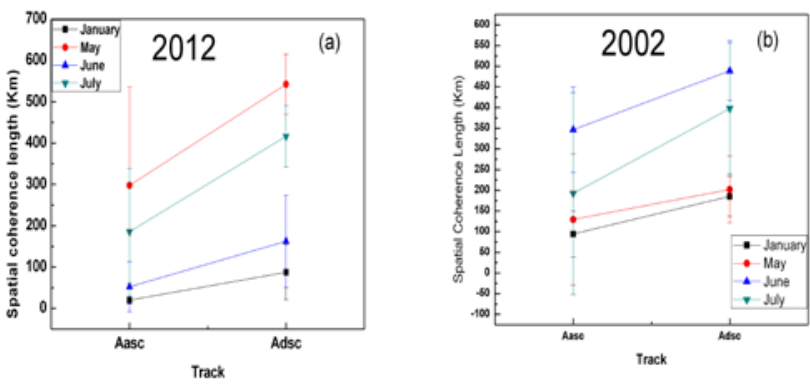

Fig. 8 - Anisotropy in spatial coherence lengths of SWH between the ascending and descending tracks during (a) 2012 and (b) 2002.The vertical bars represent the standard deviation.

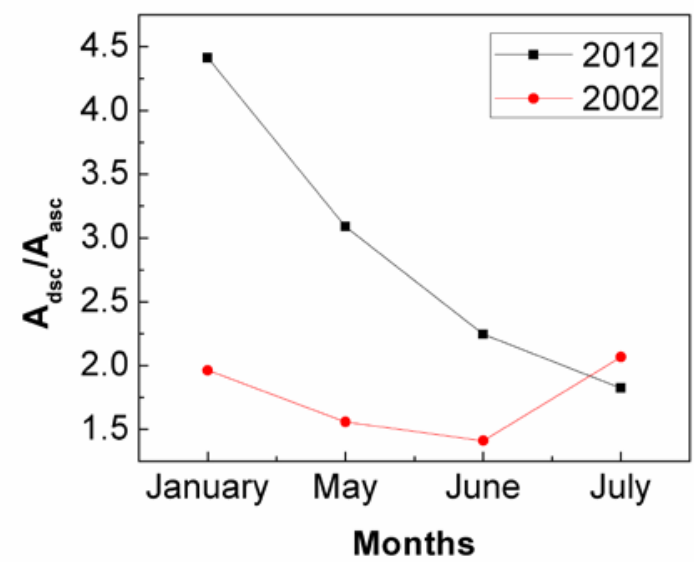

Fig. 9 - Evolution of anisotropy in spatial coherence scales of SWH over the Arabian Sea during 2002 and 2012 monsoon.

Figure 9 shows the evolution of anisotropy of SWH Coherence scales during two contrasting monsoon years of 2002 and 2012. During the poor monsoon year 2002, anisotropy registers a sharp fall in the month of July, whereas during good monsoon year 2012, it increases steadily owing to the sustained flow of monsoon winds.

\section{CONCLUSIONS}

We have examined, for the first time, the spatial coherence of oceanic parameters, based on unique near-instantaneous alongtrack sampling provided by space based Radar Altimeter measurements, and explored their association with the SW Monsoon activity over India. The spatial coherence length scales derived using ACF analysis display interesting characteristics in relation to onset and evolution of SW Monsoon. The spatial coherence scales show an increasing trend as highly sustained SW monsoon winds pick up over the Arabian Sea. Further, the spatial coherence scales and their anisotropy also show sensitivity to changing monsoon activity over the Arabian Sea.

The temporal evolution of the estimated spatial coherence scales, found to be of the order of $100-500 \mathrm{~km}$, is studied in relation to onset and evolution of SW Monsoon for two contrasting monsoon years 2002 and 2012. The temporal evolution of analyzed spatial coherence scales over Arabian Sea 
clearly brings out the distinction between a 'good' (2012) and a 'poor' (2002) monsoon year.

We have also analyzed the anisotropy of the spatial coherence lengths in a limited manner exploiting the directional sampling differences between ascending and descending tracks. The larger coherence lengths and stronger anisotropy observed over the Arabian Sea, as compared to Bay of Bengal region, clearly indicate the presence of strong sustained directional flow associated with the SW Monsoon over the Arabian Sea.

The present preliminary study has demonstrated, for the first time, the usefulness of unique RA along-track data sets in analyzing the 'spatial' structure of oceanic wind and wave fields. More detailed studies and mapping of the spatial coherence of oceanic and atmospheric parameters over different regions of the globe using two decades of highly precise radar altimeter measurements from a variety of missions are underway.

\section{ACKNOWLEDGEMENTS}

Authors would like to thank Director, ICCSIR for support and encouragement. K.H.B.S would like to thank Director, NRSC, Director, CSSTEAP, CGM, NRSC and GM, RRSC (Central) for providing opportunity to pursue a UN-CSSTEAP (Affiliated to the United Nations) course on Space and Atmospheric Science under which present study was initiated.

\section{REFERENCES}

Bhandari, S. M. and Varma, A. K.1996.Potential of simultaneous dual-frequency radar altimeter measurements from TOPEX/Poseidon for rainfall estimation over oceans, Remote. Sens. Environ, 58: 13-20.

Bhandari, S. M.1985. Project Proposal- SAC-ISRO Report, SAC/RSDA/MET/PR/01/85.

Brandt, P., Dengler, M., Rubino, A., Quadfasel, D., and Schott, F.2003.Intra-seasonal variability in the southwestern Arabian Sea and its relation to the seasonal circulation, Deep-Sea Research II, 50: 2129-2141.

Brown, G. S.1979. Estimation of surface wind speed using satellite borne radar measurements at normal incidence,” J. Geophys. Res.,84, 3974-3978.

Chelton, D. B. and Mccabe, P., J.1985. A Review of Satellite Altimeter Measurement of Sea Surface Wind Speed with a Proposed New Algorithm, J. Geophys. Res, 1985, 90: NO. C3, 4707-4720.

Chen, G., Chapron, B., Tournadre, J., Katsaros, K., and Vandemark, D.1997. Global oceanic precipitation: A joint view by TOPEX and the TOPEX microwave radiometer, J. Geophys. Res, 102: 10457-10471.

Chu, P. C., Wang, G. H. and Chen, Y. C.2002. Japan Sea thermohaline structure and circulation. Part III: Autocorrelation functions, J. Phys. Oceanogr., 32: 3596-3615.
Fedor, L. S. and Brown, G. S.1982. Wave height and wind speed measurements from the Seasat altimeter, $J$. Geophys. Res, 87: 3254 - 3260.

Gille, S. T. and Kelly, K. A.1996. Scales of spatial and temporal variability in the southern ocean, J. Geophys. Res, 1996,101: No.C4, 8759-8773.

Halpern, D. and Knox, R., A.1983. Coherence between lowlevel cloud motion vectors and surface wind measurements near $0^{0}, 152^{0} \mathrm{~W}$ from April 1979 to February 1980, Atmos. Ocean, 21: 82-93.

Liu, W. T. and P. P. Niiler.1984. Determination of monthly mean humidity in the atmospheric surface layer over oceans from satellite data, J. Phys. Oceanog., 14: 14511457.

Monaldo, F.1988. Expected differences between buoy and radar altimeter estimates of wind speed arid significant wave height and their implications on buoy altimeter comparisons, J. Geophys. Res, 93: 2285-2302.

Monaldo, F.1990. Corrected spectra of wind speed and significant wave height, J. Geophys. Res, 95: 33993402.

Ocean Observing System Devel-opment Panel (OOSDP), 1995. Scientific Design for the Common Module of the Global Ocean Observing System and the Global Climate Observing System: An Ocean Observing System for Climate. Department of Oceanography, Texas A\&M University, College Station, Texas, 265 pp.

Queffeulou, P. and Bentamy, A. 2007. Analysis of Wave Height Variability Using Altimeter Measurements: Application to the Mediterranean Sea, J. Atmos. Oceanic Technol., 24: 2078-2092.

Romanou, A., Rossow, W. B. and Chou, S. H.2006. Decorrelation Scales of High-Resolution Turbulent Fluxes at the Ocean Surface and a Method to Fill in Gaps in Satellite Data Products, J. Climate, 19: 3378-3393.

Sarkar, A., Sujit, B., Varma, A. K., and Jignesh, K..2002. Auto Correlation Analysis of Surface wind vectors, Proceedings of Indian Academy of Science (Earth Planet. Sci.), 111: No. 3, 297-303.

Sarkar, A., Jignesh, K., and Satheesan, K.2006. Auto correlation analysis of wave heights in the Bay of Bengal, J. Earth. Syst. Sci., 115: No.2, 235-237.

Tournadre, J.1993. Time and space scales of significant wave heights, J. Geophys. Res, 98: NO.C3, 4727-4738.

AVISO and PODAAC User Handbook, IGDR and GDR Jason Products,SMM-MU-M5-OP-13184-CN (AVISO),October 2008, edition 4.1.

http://www.aviso.oceanobs.com/ Data / Products / Sea-surfaceheight-products / Global / CorSSH

http://www.aviso.oceanobs.com/en/data/products/wind-wavesproducts/gdr-ogdr-osdr-ra2- wwv 
The International Archives of the Photogrammetry, Remote Sensing and Spatial Information Sciences, Volume XL-8, 2014 ISPRS Technical Commission VIII Symposium, 09 - 12 December 2014, Hyderabad, India

www.imd.gov.in/section/nhac/dynamic/endofseasonreport.pdf

www.imd.gov.in/section/nhac/dynamic/endofmonsoon2004.htm 